\title{
Estimated variability of below-cloud aerosol removal by rainfall for observed aerosol size distributions
}

\author{
C. Andronache \\ Boston College, Chestnut Hill, Massachusetts, USA \\ Received: 12 August 2002 - Published in Atmos. Chem. Phys. Discuss.: 14 November 2002 \\ Revised: 24 January 2003 - Accepted: 24 January 2003 - Published: 11 February 2003
}

\begin{abstract}
Below-cloud scavenging (BCS) coefficients of aerosols by rainfall are estimated for reported aerosol size distributions measured during field experiments in various environments. The method employed is based on explicit calculations of the efficiency of collision between a raindrop and aerosol particles. Such BCS coefficients can be used in numerical models that describe: 1) the detailed evolution of aerosol size distribution and, 2) the evolution of total aerosol mass concentration. The effects of raindrop size distribution and aerosol size distribution variability on BCS coefficients are illustrated using observed data. Results show that BCS coefficient increases with rainfall rate and has a significant dependence on aerosol size distribution parameters. Thus, BCS is important for very small particles (with diameters less than $0.01 \mu \mathrm{m}$ ) and for coarse particles (with diameters larger than $2 \mu \mathrm{m}$ ). For rainfall rate $R \sim 1 \mathrm{~mm} \mathrm{hr}^{-1}$, the 0.5 -folding time of these particles is of the order of one hour. It is shown that BCS is negligible for aerosol particles in the range [0.1-1] $\mu \mathrm{m}$ if compared with in-cloud scavenging rates for low and moderate rainfall rates $\left(R \sim 0.1-10 \mathrm{~mm} \mathrm{hr}^{-1}\right)$. The results indicate that a boundary layer aerosol size distribution with coarse mode is drastically affected very shortly after rain starts (in a fraction of one hour) and consequently, the below-cloud aerosol size distribution becomes dominated by particles in the accumulation mode.
\end{abstract}

\section{Introduction}

The scavenging of aerosol particles (AP) by dry deposition and precipitation represent important processes by which a balance is maintained between the sources and sinks of airborne particles. The wet removal by precipitation is by far the most efficient atmospheric aerosol sink and the detailed mechanism of this process involves microphysical interac-

Correspondence to: C. Andronache (andronac@bc.edu) tions between AP and hydrometeors (Pruppacher and Klett, 1997). For practical reasons, the APs wet removal is typically represented in current models by scavenging coefficients in aerosol mass continuity equations. These scavenging coefficients are determined to be a function of bulk quantities available from measurements, such as the precipitation rate at the ground. While significant experimental and theoretical work has been dedicated to estimate the scavenging coefficients under a variety of conditions (Wang and Pruppacher, 1977; Grover et al., 1977; Wang et al., 1978; Slinn, 1983), recent reports show that the representation of aerosol removal processes in current aerosol transport models remains a source of uncertainty (Rasch et al., 2000). In addition, the understanding of wet removal processes remains crucial in local and regional pollution studies (Dana and Hales, 1976; Radke et al., 1980; Scott, 1982; Chang, 1986; Jylha, 1991, 1999; Sparmacher et al., 1993; Okita et al., 1996; Mircea et al., 2000).

An AP can be removed from atmosphere by (1) nucleation scavenging or by (2) impaction scavenging. In nucleation scavenging, APs serve as cloud condensation nuclei (CCN) or ice nuclei (IN) in the initial stage of cloud formation and these processes are controlled by the requirements for heterogeneous nucleation in the atmosphere such as supersaturation. In contrast, the impaction scavenging depends on the net action of various forces influencing the relative motion of APs and hydrometeors. Nucleation scavenging dominates the impaction scavenging at the beginning of cloud formation and experimental and model results show that this process can deplete the original aerosol population in air up to 75-90\% (Junge, 1963; Flossmann et al., 1985, 1987; Ten Brink et al., 1987; Schumann, 1991). A fraction of APs that are not scavenged by nucleation might become incorporated into cloud and precipitation hydrometeors through impaction scavenging. Similar mechanisms act during in-cloud scavenging (ICS) and below-cloud scavenging (BCS). These mechanisms are: convective Brownian diffusion, intercep-

(C) European Geosciences Union 2003 
tion, inertial impaction, thermophoresis, diffusionphoresis, airflow turbulence and electrostatic attraction (a literature review on these processes is given by Pruppacher and Klett, 1997). One significant difference between the ICS and BCS processes is that the in-cloud interstitial aerosol grows typically into cloud droplet (with a diameter of about $10 \mu \mathrm{m}$ ), which makes the collection by falling raindrops very efficient. While the BCS is less efficient than the ICS, there are several environmental conditions when this process is important, especially in cases when mechanical generated large particles are present near the Earth's surface as will be illustrated in this paper.

Major work has been done in the last decades to characterize the BCS based on the concept of efficiency of collision between a falling raindrop and aerosol particles. Earlier work by Greenfield (1957) recognized the role of Brownian motion in increasing efficiency of collision between the raindrop and the very small aerosol particles (with diameters $d_{p}<0.01 \mu \mathrm{m}$ ). Similarly, large particles (with diameters $d_{p}>2 \mu \mathrm{m}$ ) tend to have high collision efficiency because of their inertia. The particles with diameters in the range 0.01 and $2 \mu \mathrm{m}$ appeared to have a very small efficiency of collision and this size range is named "scavenging gap". Further work by Slinn and Hales (1971) showed that the thermophoresis could enhance the BCS of aerosols with diameters in the range [0.01-1] $\mu \mathrm{m}$. Following experimental work and model results by Grover et al. (1977), Wang et al. (1978), Byrne and Jennings (1993), showed that the presence of charge on aerosol particles and raindrops can substantially increase the BCS of aerosols with sizes in the "scavenging gap". More recent model estimations by Tinsley et al. (1999) indicate that BCS can be increased significantly for aerosols resulted from evaporation of charged cloud drops. Given the complexity of BCS processes, there is no simple general theory to account for all aerosol sizes and for all atmospheric conditions. Particularly, the variability of phoretic forces, electric charge and turbulence tend to affect the BCS of accumulation mode particles and this variability is reflected in the reported experimental and model BCS coefficient values. While many studies were dedicated to determine the efficiency of collision between raindrops and aerosols of specific particle sizes, there are very few applications of the BCS model to observed ambient aerosol and raindrop size distributions. Earlier calculations by Dana and Hales (1976) indicated that the BCS coefficient for a polydisperse aerosol is generally larger than it would be for a monodisperse aerosol with size equal to some typically used distribution parameter. These studies suggested a need for extensive application of the BCS model to observed atmospheric aerosol size distributions.

The purpose of this study is to analyze the dependence of below-cloud aerosol mass scavenging on observed aerosol size distribution characteristics and on rainfall rate. The practical outcomes of this paper are BCS coefficients that can be used in numerical models to describe the boundary layer
(BL) aerosol changes due to precipitation. The presented results are suitable for two modeling approaches. One approach is the study of the evolution of detailed bin resolved aerosol mass size distribution (as in the case of analysis of high resolution aerosol measurements from field experiments). The second approach is the study of evolution of the total aerosol mass concentration during rain events (as in the case of local and regional models used in pollution studies). First, we describe the basic concepts used to determine the mass scavenging coefficient suitable for a mass continuity equation (both for models that describe bin size distribution evolution and for total mass concentration evolution). Then we calculate the mass scavenging coefficient for a variety of aerosol size distributions determined from reported field experimental data with a significant number of samples. Calculations are made for a variety of rainfall rates for cases with coarse mode and for cases dominated by submicron particles. Calculations are compared with experimental results and the implications of BCS on the aerosol 0.5-folding time and on the changes of aerosol size distribution in the BL are discussed.

\section{Method}

The method used here to evaluate the BCS coefficients is based on the concept of efficiency of collision between an AP and a raindrop (Slinn, 1983; Pruppacher and Klett, 1997; Seinfeld and Pandis, 1998). When a raindrop of diameter $D_{p}$ falls below the cloud, it creates an airflow with streamlines that deviates from the drop surface. Some of the aerosol particles present in the swept out volume of the raindrop collide with the raindrop and are collected. The total rate of collection of mass of all aerosol particles of diameter $d_{p}$ is

$n_{M}\left(d_{p}\right) d d_{p} \int_{0}^{\infty} \frac{\pi}{4} D^{2} U_{t}\left(D_{p}\right) E\left(D_{p}, d_{p}\right) n_{D}\left(D_{p}\right) d D_{p}$

where: $n_{M}\left(d_{p}\right)$ is the mass size distribution of aerosol, $U_{t}\left(D_{p}\right)$ is the raindrop terminal velocity, $n_{D}\left(D_{p}\right)$ is the raindrop size distribution, and $E\left(D_{p}, d_{p}\right)$ is the collection efficiency, which is assumed to be equal with the collision efficiency (Slinn, 1983). In these calculations, the raindrop terminal velocity is taken as $U_{t}\left(D_{p}\right)=130 \times D_{p}^{0.5}$, which is a good fit of the experimental data (with $U_{t}$ in $\mathrm{ms}^{-1}$ and $D_{p}$ in $\mathrm{m})$ (Kessler, 1969). The collection efficiency is defined as the ratio of aerosol mass collected by a drop and the aerosol mass in the swept out volume. The raindrop size distribution is described by an empirical Marshall and Palmer fit, $n_{D}\left(D_{p}\right)=$ $N_{D 0} \exp \left(-c D_{p}\right)$, where $N_{D 0}=8 \times 10^{3} \mathrm{~m}^{-3} \mathrm{~mm}^{-1}$, and $c=4.1 R^{-0.21} \mathrm{~mm}^{-1}$, where $R$ is the rainfall rate in $\mathrm{mm} \mathrm{hr}^{-1}$ (Marshall and Palmer, 1948). For practical calculations, the raindrop size distribution, $n_{D}\left(D_{p}\right)$ is linked to rainfall rate, $R$, by

$R=\frac{\pi}{6} \int_{0}^{\infty} D_{p}^{3} U_{t}\left(D_{p}\right) n_{D}\left(D_{p}\right) d D_{p}$ 


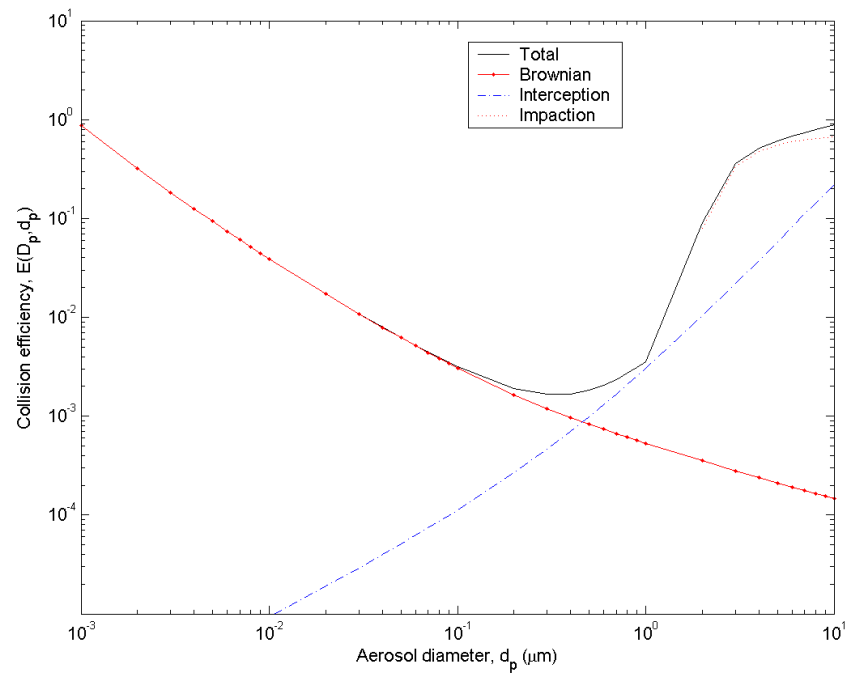

Fig. 1a. Contributions to the collision efficiency, $E$, between a raindrop of diameter $D_{p}=0.1 \mathrm{~mm}$ and an aerosol particle of diameter $d_{p}$ : Total (black solid line), Brownian (red solid line with dots), Interception (blue dashed line), and Impaction (red dotted line).

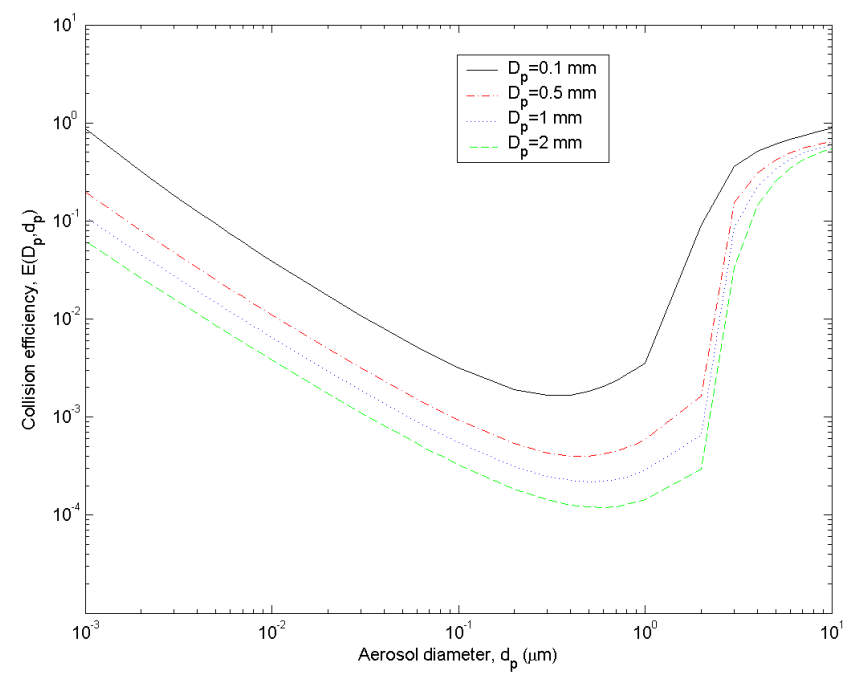

Fig. 1b. Collision efficiency versus aerosol diameter for several raindrop diameters.

The BCS rate of aerosol of diameter $d_{p}$ can be written as

$\frac{d n_{M}\left(d_{p}\right)}{d t}=-L\left(d_{p}\right) n_{M}\left(d_{p}\right)$

$L\left(d_{p}\right)=\int_{0}^{\infty} \frac{\pi}{4} D_{p}^{2} U_{t}\left(D_{p}\right) E\left(D_{p}, d_{p}\right) n_{D}\left(D_{p}\right) d D_{p}$

where $L\left(d_{p}\right)$ is the scavenging coefficient of particles of diameter $d_{p}$. Thus, $L\left(d_{p}\right)$ represents the relative variation of aerosol mass concentration per unit time for particles of diameter $d_{p}$, due to aerosol removal by falling raindrops in the BL.

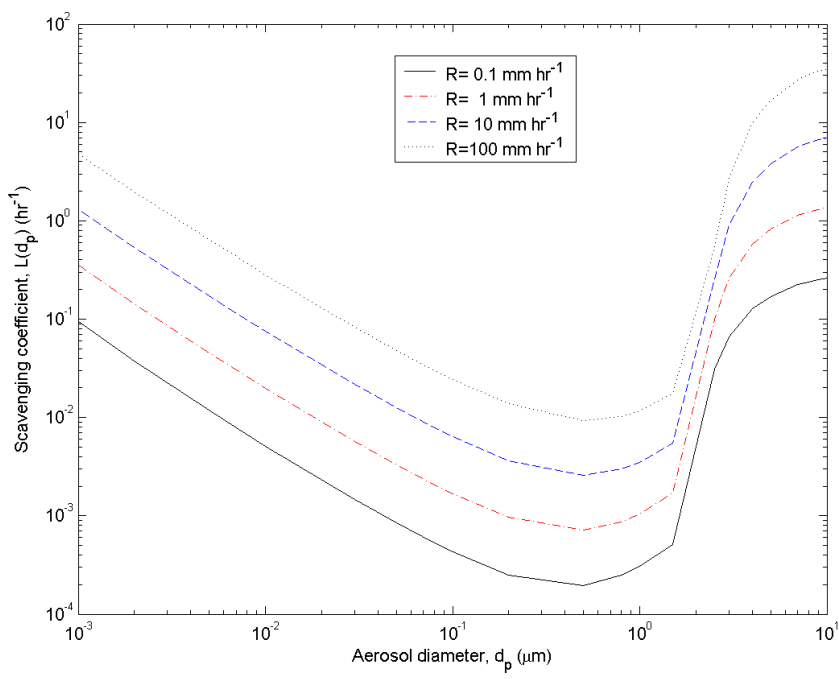

Fig. 2a. Mass scavenging coefficient $L\left(d_{p}\right)$ for aerosol of diameter $d_{p}$ scavenged by precipitation with a rainfall rate $R$.

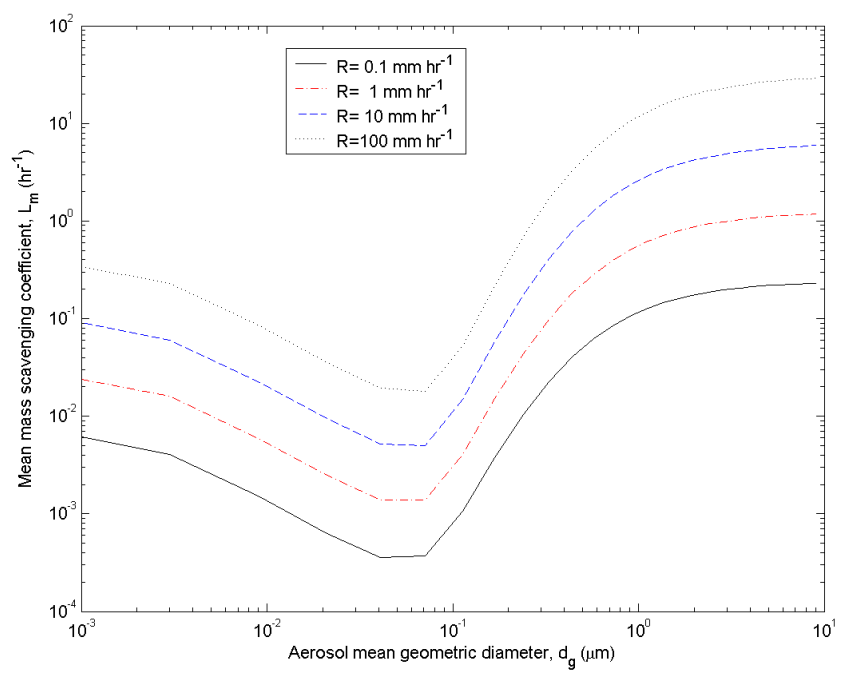

Fig. 2b. Mean mass scavenging coefficient, $L_{m}$, versus the aerosol geometric mean diameter $\left(d_{g}\right)$ for several rainfall intensities. (Calculations are for one log-normal mode of aerosol size distribution with $\sigma_{g}=2$ ).

The raindrop-aerosol collision efficiency $E\left(D_{p}, d_{p}\right)$ has been evaluated both theoretically and experimentally in a series of previous papers (as reviewed by Pruppacher and Klett, 1997, Chapter 17). For practical considerations, the available $E$ data are fitted into an expression that covers a wide range of aerosol particle sizes. Based on Slinn (1983) we use the expression of $E$ that is summarized by Seinfeld and Pandis (1998) (Eq. 20.56). Figure 1a illustrates the role of various terms that contribute to the collision efficiency, $E$, between a raindrop of diameter $D_{p}=0.1 \mathrm{~mm}$ and an aerosol particle of diameter $d_{p}$ : the Brownian diffusion dominates $E$ 
for particles with diameters $d_{p}<0.01 \mu \mathrm{m}$, while the interception and impaction become important for larger particles with $d_{p}>1 \mu \mathrm{m}$. The effect of raindrop size on the collision efficiency is illustrated in Fig. 1b. Thus, small aerosol particles are collected more efficient by smaller raindrops than by large raindrops. For coarse aerosol particles, due to important inertial term, there are fewer differences in $E$ due to raindrop sizes. The variation of the scavenging coefficient of particles of diameter $d_{p}, L\left(d_{p}\right)$, given by Eq. (4) is illustrated in Fig. 2a as a function of particle size and rainfall rate, $R$. For a given aerosol size, we note a variation of about 2 orders of magnitude as $R$ varies between 0.1 and $100 \mathrm{~mm} \mathrm{hr}^{-1}$, which is a range that covers most of the observed precipitation rates. $L\left(d_{p}\right)$ is suitable for description of mass evolution in each bin centered on diameter $d_{p}$.

The total mass scavenging rate is given by

$$
\frac{d M_{a}}{d t}=-\int_{0}^{\infty} \frac{\pi}{6} d_{p}^{3} \rho_{p} L\left(d_{p}\right) n\left(d_{p}\right) d d_{p}=-L_{m} M_{a}
$$

where, $M_{a}$ is the total aerosol mass concentration, $\rho_{p}$ is the aerosol density. The mean mass scavenging coefficient, $L_{m}$, is defined by

$L_{m}=\frac{\int_{0}^{\infty} d_{p}^{3} L\left(d_{p}\right) n\left(d_{p}\right) d d_{p}}{\int_{0}^{\infty} d_{p}^{3} n\left(d_{p}\right) d d_{p}}$

where the number size distribution of aerosol, $n\left(d_{p}\right)$ is typically represented as a sum of three log-normal modes. $L_{m}$ is the relative variation of the total aerosol mass concentration per unit time due to aerosol removal by collisions with falling raindrops in the BL. Thus, $L_{m}$ is suitable for models based on total aerosol mass concentration continuity equation. Figure $2 \mathrm{~b}$ shows the mean mass scavenging coefficient, $L_{m}$, versus the aerosol geometric mean diameter $\left(d_{g}\right)$ for several rainfall intensities (calculations are shown for one log-normal mode of aerosol size distribution with $\sigma_{g}=2$ ). This plot illustrates that for a single mode, $L_{m}$ is dependent on the mean geometric diameter while preserving a similar dependence on $R$ as $L\left(d_{p}\right)$. Furthermore, it has been shown that increasing $\sigma_{g}$, the collision efficiency, $E$, tends to increase and the "scavenging gap" becomes partially filled (Dana and Hales, 1976; Slinn, 1983; Seinfeld and Pandis, 1998).

Calculations presented in this paper are based on the Marshall and Palmer (MP) raindrop size distribution (which for the following discussion is called the standard distribution). The MP raindrop size distribution describes well the population of raindrops under a wide range of rainfall rates and rain types, provided that sufficient averaging on measured data is performed. The MP fit tends to overestimate the number of very small raindrops $\left(D_{p}<0.1 \mathrm{~mm}\right)$ but the contribution of these drops to the total rainfall rate $R$ is small. To capture the role of very small raindrops, it is more appropriate to use a raindrop size distribution approximated by a gamma function (Ulbrich, 1983). Also, for the description of the raindrop size distribution from measurements taken with a frequency

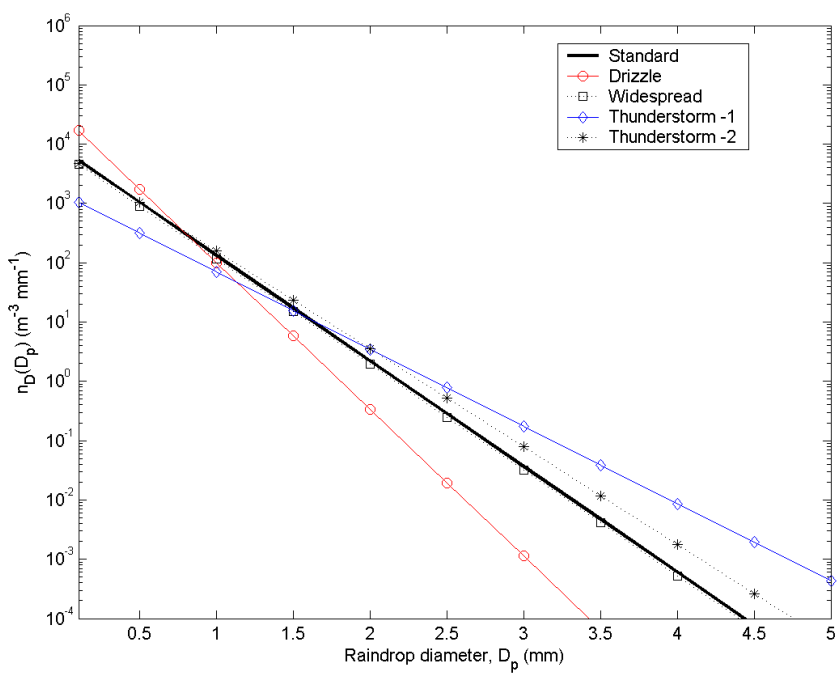

Fig. 3a. Raindrop size distributions from several field measurements: Standard refers to the original Marshall and Palmer size distribution; Drizzle, Widespread and Thunderstorm -1 are from Joss et al. (1968), and Thunderstorm -2 is based on Sekhon and Srivastva (1971)

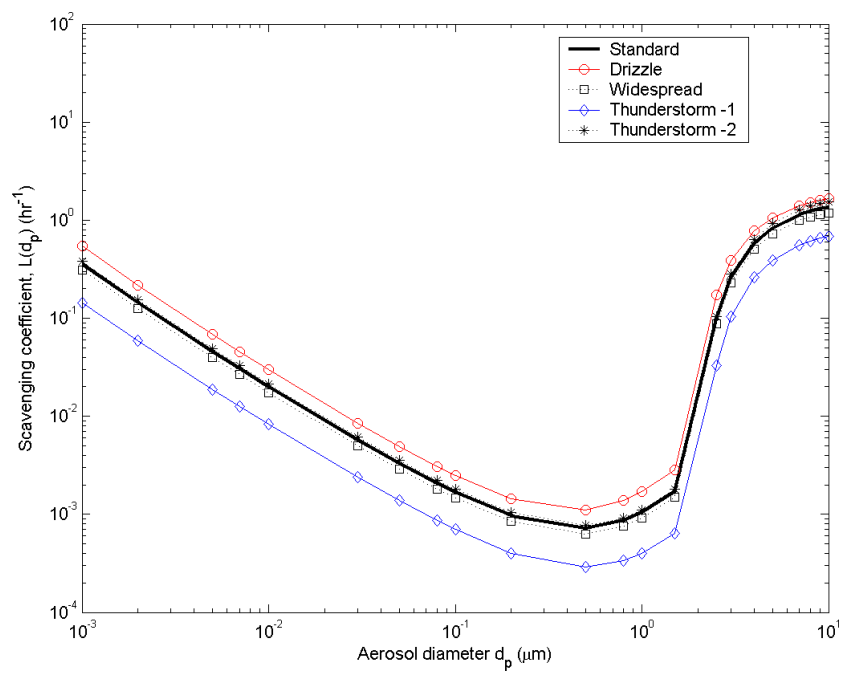

Fig. 3b. Scavenging coefficient $L\left(d_{p}\right)$ versus aerosol diameter for the the same raindrop size distributions. The plots are for $R=1$ $\mathrm{mm} \mathrm{hr} \mathrm{h}^{-1}$.

of $1 \mathrm{~min}$ or less, the gamma function is a better approximation. For the problem treated here, where we express the BCS coefficients as function of rainfall rate, the average raindrop size distribution is a good approximation and is generally well described by the standard MP fit. Figure 3a shows several MP size distributions compared with the standard fit. Note that the standard fit is very close to the case described as widespread rain as well as to the thunderstorm cases. The drizzle case has more small raindrops per unit volume, while 
Table 1. Log-normal size distribution parameters for cases with coarse mode

\begin{tabular}{cccccccccl}
\hline $\begin{array}{c}N_{1} \\
\left(\mathrm{~cm}^{-3}\right)\end{array}$ & $\begin{array}{c}N_{2} \\
\left(\mathrm{~cm}^{-3}\right)\end{array}$ & $\begin{array}{c}N_{3} \\
\left(\mathrm{~cm}^{-3}\right)\end{array}$ & $\begin{array}{c}d_{p 1} \\
(\mu \mathrm{m})\end{array}$ & $\begin{array}{c}d_{p 2} \\
(\mu \mathrm{m})\end{array}$ & $\begin{array}{c}d_{p 3} \\
(\mu \mathrm{m})\end{array}$ & $\sigma_{1}$ & $\sigma_{2}$ & $\sigma_{3}$ & Notes \\
\hline 3200 & 2900 & 0.300 & 0.020 & 0.116 & 1.800 & 1.45 & 1.65 & 2.39 & (a) remote cont. \\
6650 & 147 & 1990 & 0.015 & 0.054 & 0.084 & 1.67 & 3.60 & 1.84 & (a) rural \\
133 & 66.6 & 3.1 & 0.080 & 0.266 & 0.580 & 4.53 & 1.62 & 2.48 & (a) marine \\
9900 & 1110 & 3640 & 0.013 & 0.014 & 0.050 & 1.75 & 4.64 & 2.17 & (a) urban \\
129 & 59.7 & 63.5 & 0.007 & 0.250 & 0.520 & 4.41 & 1.79 & 2.66 & (a) free trop. \\
21.7 & 0.186 & $3 \times 10^{-4}$ & 0.138 & 0.750 & 8.600 & 1.75 & 1.99 & 1.95 & (a) polar \\
726 & 114 & 0.178 & 0.002 & 0.038 & 21.60 & 1.76 & 5.88 & 2.74 & (a) desert \\
70 & 3 & 0.05 & 0.200 & 2.000 & 12.00 & 1.90 & 2.00 & 3.00 & (b) marine \\
210 & 74 & 15 & 0.033 & 0.110 & 0.540 & 1.40 & 1.41 & 2.02 & (c) marine \\
33 & 200 & 20 & 0.020 & 0.090 & 0.550 & 1.40 & 1.60 & 2.50 & (d) dust layer \\
\hline
\end{tabular}

(a) Compiled size distributions for several aerosol types (Jaenicke, 1993);

(b) Marine aerosol measurements in North East Atlantic MBL under surface wind speed of $17 \mathrm{~ms}^{-1}$ (O'Dowd et al., 1997);

(c) Marine aerosol measured in South Pacific MBL during ACE 1 (Bates et al., 1998);

(d) Dust layer sampled at $2.7 \mathrm{~km}$ altitude over North Atlantic during ACE 2 (de Reus et al., 2000)

the thunderstorm cases tend to have smaller number of larger raindrops per unit volume, when compared with the standard fit. The dependence of the scavenging coefficient on raindrop size distribution is illustrated in Figure $3 b$ for the cases presented in Figure 3a (for $R=1 \mathrm{~mm} \mathrm{hr}^{-1}$ ). We note that $L\left(d_{p}\right)$ becomes enhanced for drizzle case and less efficient for thunderstorm cases, which is consistent with the dependence on the raindrop size. Similar results and variability are found for other rainfall rates. Overall, we found that $L\left(d_{p}\right)$ has a weak dependence on the particular raindrop size distributions used in calculations. The dependence of $L\left(d_{p}\right)$ on rainfall rate and aerosol size are the most important factors of BCS coefficient variability as will be shown in the next section.

\section{Results}

The model described above is applied to selected available data of aerosol size distributions measured in various environments. It has been recognized that detailed in situ measurements of the full aerosol size spectrum as a function and time and space are still insufficient in order to characterize the variability of aerosol properties on a global scale. Furthermore, most of the experimental data of BCS coefficients are limited to laboratory studies and to a subset of aerosol sizes, in the submicron range due to the work related to wet deposition of radionuclides (Sparmacher et al., 1993). In this work we use detailed size distribution measurements taken over sufficient time intervals in recent field experiments. The results are presented in two parts: (1) calculated BCS coefficients for the full spectrum of aerosol size distribution, in cases where three log-normal modes were found to describe the size distribution: Aitken, accumulation, and coarse parti- cles; (2) calculated BCS coefficient for measured size distributions with predominant submicron particles.

\subsection{Below-cloud scavenging of coarse particles}

Several cases of aerosol size distribution with coarse mode are used in this section and the log-normal size distribution parameters are summarized in Table 1. Jaenicke (1993) reported aerosol size distributions for several environments: polar, free troposphere, marine, remote continental, desert dust storm, rural, and urban. For each type of aerosol, the size distribution is represented as a sum of three log-normal distributions. We calculated the mean mass scavenging coefficient $L_{m}$ for these aerosol types to compare with data from various recent cases. Generally, we found relatively high values of $L_{m}$, which are caused by the presence of coarse mode as will become clear from the few cases illustrated below.

One instance where coarse mode might be important is the marine boundary layer (MBL) under significant wind conditions near the ocean surface. The ocean is a source of sea salt particles to the atmosphere, and such particles are created during bursting of air bubbles due to breaking waves and spume and splash droplets. These particles are in small number but they can dominate the mass size distribution and can be important in chemical reactions in the marine BL (O'Dowd et al., 1997; Bates et al., 1998). Breaking waves (at wind, $w \sim 3-4 \mathrm{~ms}^{-1}$ ) produce bubbles that can generate about 10 jet drops with sizes around $1-2 \mu \mathrm{m}$ up to $10 \mu \mathrm{m}$ and hundreds of film drops in the submicron range. For $w$ larger than $7-11 \mathrm{~ms}^{-1}$, the tearing of wave crests produces ultra large spume sea-salt particles (O'Dowd et al., 1997). Using a combination of optical particles counters (Particle Measuring Systems ASASP-X, FSSP, and OAP), O'Dowd et al. (1997) compiled a data set of size distribution measure- 

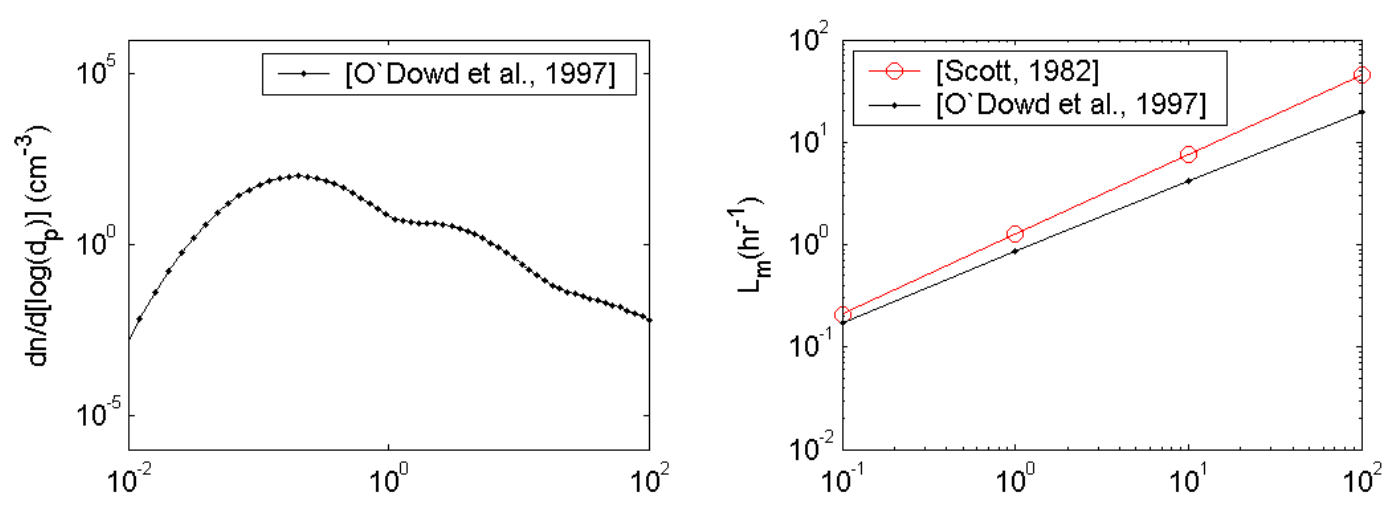

(c)

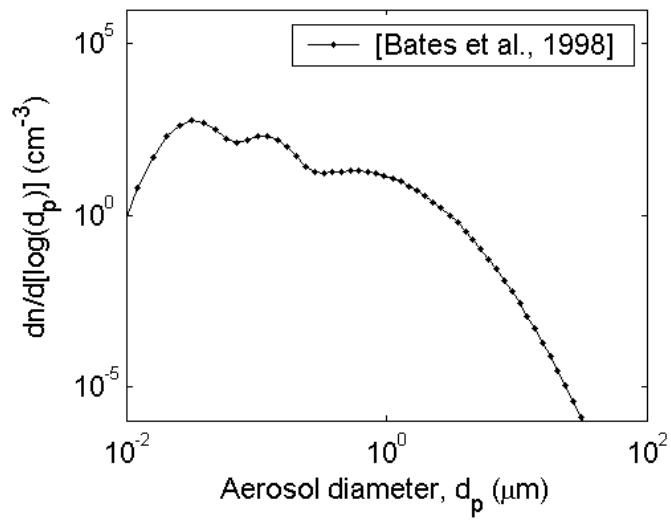

(d)

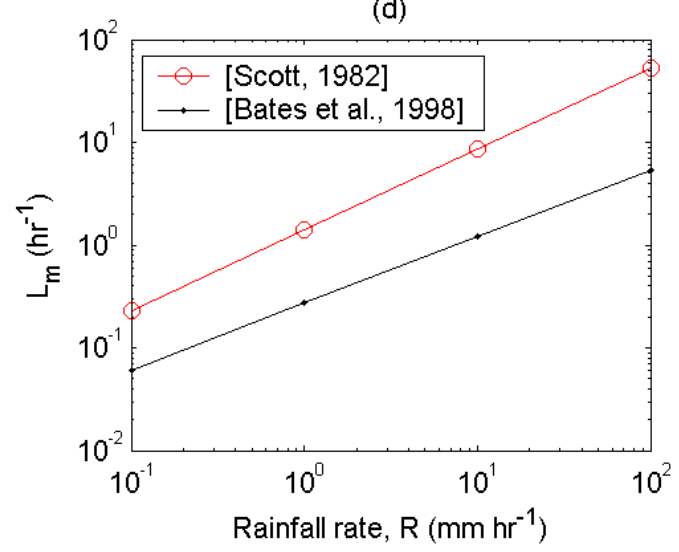

Fig. 4. (a) Marine aerosol size distribution measured in Northeast Atlantic (O'Dowd et al., 1997), (b) the corresponding mean mass scavenging coefficient; (c) marine aerosol size distribution measured in South Pacific (Bates et al., 1998) and (d) the corresponding mean mass scavenging coefficient. The in-cloud scavenging coefficient based on Scott [1982] is shown for comparison.

ments that cover the range 0.05 to $150 \mu \mathrm{m}$ radius and wind speeds up to $17 \mathrm{~ms}^{-1}$. The $\log$ normal fit for $w=17 \mathrm{~ms}^{-1}$ is shown in Fig. 4a and the calculated $L_{m}$ is depicted in Fig. 4b. For comparison, we plotted the ICS coefficient based on the method described by Scott (1982). The ICS coefficient is calculated assuming that aerosol particles that enter into cloud are activated as $\mathrm{CCN}$ and grow to form a narrow cloud drop size distribution with a typical diameter of $\sim 10 \mu \mathrm{m}$. Falling raindrops in cloud collects some of these cloud drops. The physics of collection is similar with the one described above for the BCS mechanism but it is dominated by inertial impaction (Scott selected a value $E=0.65$ for the collection efficiency between raindrops and cloud drops). Results from this ICS model are well supported by field measurements of the ICS coefficient (Okita et al., 1996; Jylha, 1991). These results are used here for comparisons with estimated BCS coefficients for several field cases. Overall, we found that the BCS coefficient is smaller than the ICS coefficient for all conditions considered here. However, we note that aerosol that exhibits coarse mode (for which $E$ is high due to interception and impaction terms) tends to be very efficiently removed by BCS.
Similar results are obtained using aerosol size distributions reported by Bates et al. (1998). The measurements of marine aerosol were taken aboard of the NOAA Ship Discoverer during ACE 1 (Intensive 15 November to 14 December 1995) in South Pacific (in the region $40-50^{\circ} \mathrm{S}, 135-155^{\circ} \mathrm{E}$ ). The number size distribution between 5 and $600 \mathrm{~nm}$ was measured with two differential mobility particle sizers (DMPS). The number distribution between 0.6 and $9.6 \mu \mathrm{m}$ was measured with an aerodynamic particle sizer (APS). The size distribution is shown in Fig. 4c and the corresponding BCS coefficient, $L_{m}$, in Fig. 4d. The results illustrated here suggest that under significant wind near the ocean surface, the BCS is dominated by the removal of coarse sea-salt aerosols.

Another example that illustrates the role of coarse particles in BCS is provided by a dust layer measurement over the North Atlantic Ocean during ACE2, near Tenerife, Canary Islands in July 1997 (de Reus et al., 2000). Five instruments were used to derive the aerosol size distribution of particles with diameters ranging from 0.006 to $31 \mu \mathrm{m}$ in a dust layer sampled between 2.5 and $5.5 \mathrm{~km}$ altitude. Results are shown in Fig. 5a for size distribution and Fig. 5b for BCS coefficient for data corresponding to a $2.7 \mathrm{~km}$ altitude. Overall, 

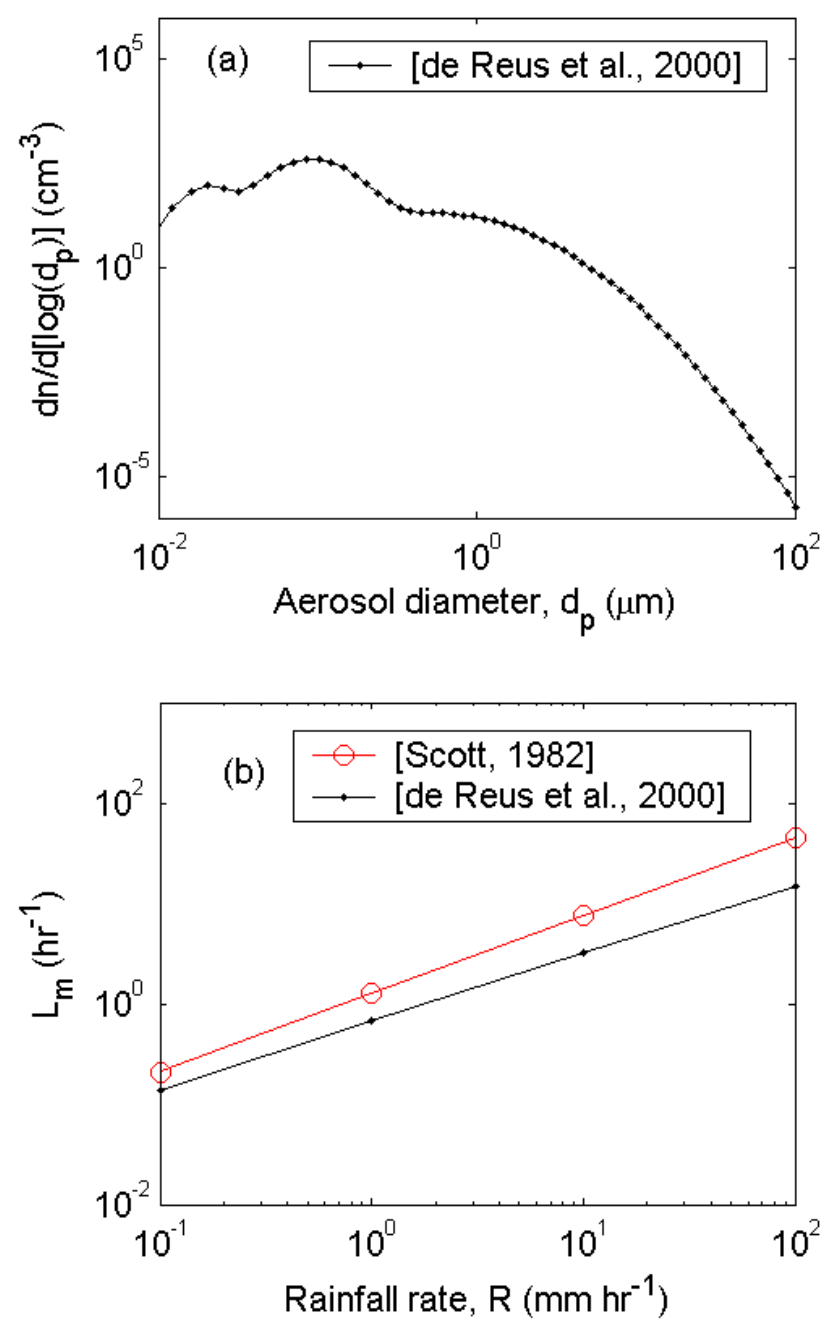

Fig. 5. (a) Aerosol size distribution of a dust layer measured over the North Atlantic Ocean on 8 July 1997 during ACE 2 (de Reus et al., 2000), (b) the corresponding calculated mean mass scavenging coefficient, $L_{m}$. The in-cloud scavenging coefficient based on Scott [1982] is shown for comparison.

the results presented for these cases are comparable with calculations based on Jaenicke (1993) data and comparable with ICS coefficient calculations, which indicates that marine and dust coarse particles are efficiently removed by BCS. In contrast, cases of aerosol distributions dominated by submicron particles, show less BCS removal as it is illustrated in the next section.

3.2 Below-cloud scavenging of predominantly submicron particles

Many submicron aerosol size distributions were reported for marine and continental locations (Van Dingenen et al., 1995; Covert et al., 1996; Jensen et al., 1996; Raes et al., 1997; Bates et al., 1998; Brechtel et al., 1998; Weingart-

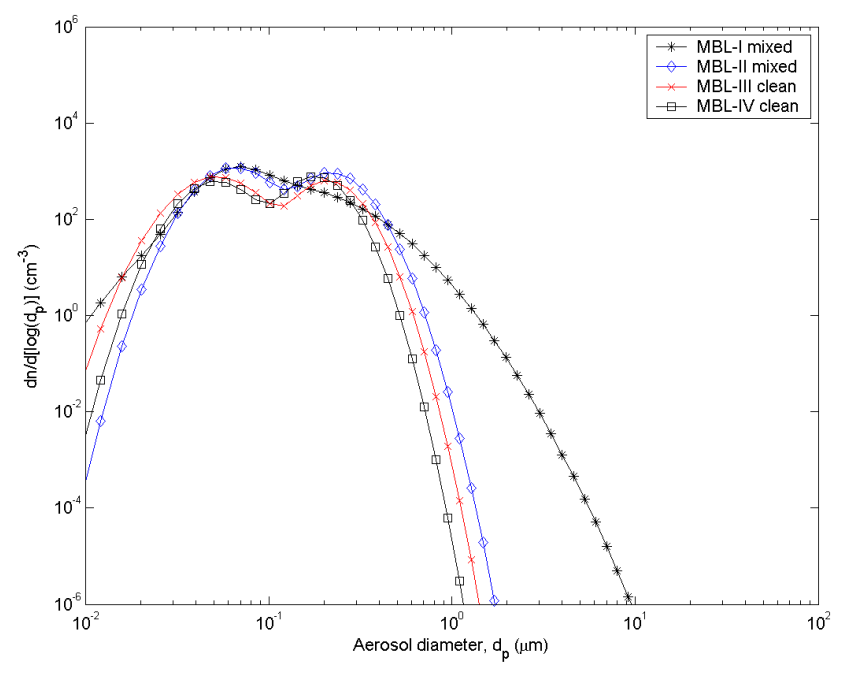

Fig. 6a. Marine boundary layer aerosol size distribution observed in North Atlantic during July, 1994 at Tenerife, Canary Islands (Raes et al., 1997) (mixed cases refer to MBL aerosol mixed with FT aerosol; clean cases refer to aerosol that stayed predominantly in the MBL unperturbed by FT or continental sources.

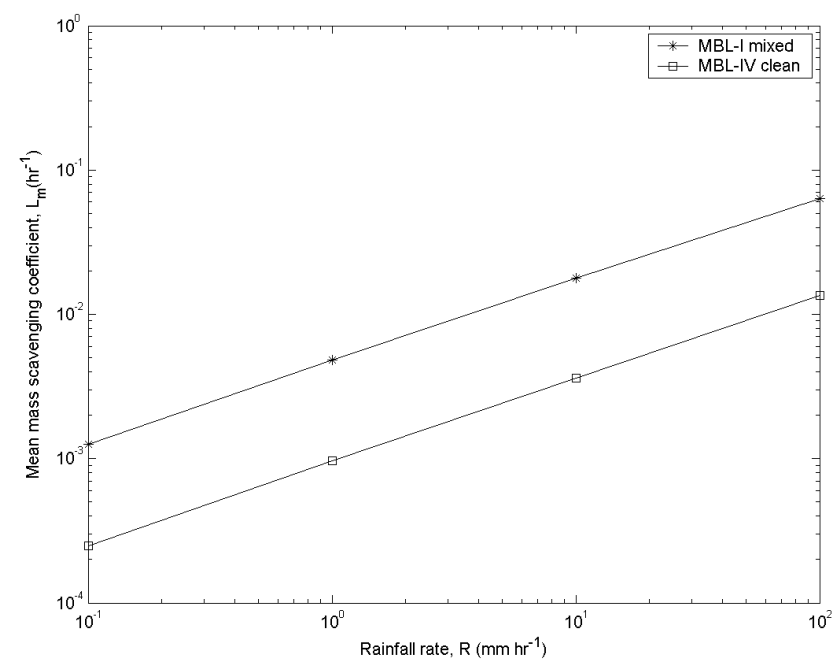

Fig. 6b. Corresponding mean mass scavenging coefficient, $L_{m}$ for a mixed case and a clean case.

ner et al., 1999). Particularly, in marine environment under calm wind conditions, the Aitken and accumulation modes are dominant and significant effort has been dedicated to describe the accumulation mode, which is responsible for direct and indirect radiative effects (Charlson et al., 1992; Twomey, 1991; IPCC, 1996). To describe the complete aerosol size spectrum, the measurements must involve a set of several instruments that simultaneously measure different size ranges. Most of the data used in this section were limited to submicron sampling, generally for environmental conditions in which these modes were dominant and the mechan- 
Table 2. Log-normal size distribution parameters for selected cases of submicron aerosol measurements

\begin{tabular}{ccccccl}
\hline $\begin{array}{c}N_{1} \\
\left(\mathrm{~cm}^{-3}\right)\end{array}$ & $\begin{array}{c}N_{2} \\
\left(\mathrm{~cm}^{-3}\right)\end{array}$ & $\begin{array}{c}d_{p 1} \\
(\mu \mathrm{m})\end{array}$ & $\begin{array}{c}d_{p 2} \\
(\mu \mathrm{m})\end{array}$ & $\sigma_{1}$ & $\sigma_{2}$ & Notes \\
\hline 319 & 349 & 0.066 & 0.120 & 1.38 & 2.00 & (a) MBL-I mixed \\
447 & 325 & 0.065 & 0.217 & 1.41 & 1.38 & (a) MBL-II mixed \\
321 & 207 & 0.052 & 0.209 & 1.47 & 1.35 & (a) MBL-III clean \\
228 & 249 & 0.052 & 0.178 & 1.40 & 1.34 & (a) MBL-IV clean \\
140 & 120 & 0.065 & 0.220 & 1.47 & 1.31 & (b) 22APR93 \\
280 & 187 & 0.055 & 0.185 & 1.35 & 1.42 & (b) 5DEC93 \\
1640 & 40 & 0.012 & 0.140 & 1.72 & 1.36 & (b) 7APR93 \\
285 & 80 & 0.030 & 0.165 & 1.47 & 1.33 & (b) 11APR93 \\
370 & 215 & 0.032 & 0.120 & 2.07 & 1.83 & (c) clear sky \\
518 & 274 & 0.042 & 0.152 & 1.94 & 1.65 & (c) light \\
454 & 303 & 0.038 & 0.134 & 1.72 & 1.69 & (c) moderate \\
413 & 259 & 0.040 & 0.137 & 1.68 & 1.70 & (c) dense \\
312 & 318 & 0.042 & 0.125 & 1.54 & 1.77 & (c) very dense \\
\hline
\end{tabular}

(a) Marine aerosol measured in North Atlantic MBL (mixed refers to MBL air mixed with FT air, and clean refers to air that stayed predominantly in the MBL without contamination from FT or continental air) (Raes et al., 1997);

(b) Cases of marine aerosol measured in mid-Pacific MBL (Covert et al., 1996);

(c) Alpine aerosol measured at Jungfraujoch, Switzerland under various cloudiness conditions (Weingartner et al., 1999).

ical aerosol production was small (Table 2). These cases are used to illustrate that BCS of submicron particles is generally less efficient, while it can still be an important process for removal of pollution especially for very intense precipitation conditions.

During July 1994, the submicron aerosol size distribution was measured on Tenerife, Canary Islands by Raes et al. (1997). The measurements were taken using a differential mobility particle sizer (TSI DMPS model 3932) operating in the size range between 16 and $620 \mathrm{~nm}$. During these measurements in North Atlantic the production of aerosol particles by sea spray was neglected because the average wind speed at Tenerife was about $5 \mathrm{~ms}^{-1}$. Four cases based on average MBL aerosol size distribution properties are shown in our analysis: the mixed cases refer descending air massed from free troposphere (FT) into the MBL. The clean cases refer to aerosol that persisted in the MBL without significant perturbation from the FT or from continental sources (Fig. 6a). For detailed description of conditions that formed these aerosol size distributions see Raes et al. (1997). In this case, the observed aerosol size distribution is dominated by Aitken and accumulation modes. The calculated BCS coefficient $L_{m}$ is shown in Fig. 6b for two cases. These BCS coefficient values are significantly smaller than those found for cases of marine aerosol with coarse mode.

Aerosol measurements were made in mid-Pacific along longitude $140^{\circ} \mathrm{W}$ from $55^{\circ} \mathrm{N}$ to $70^{\circ} \mathrm{S}$ for 90 days in 1992 and 1993 (Covert et al., 1996). The number size distribution of the particles was measured with a differential mobility particle sizer (DMPS) covering the range 20 to $600 \mathrm{~nm}$.
The cases shown here are representative for observed meteorological, aerosol sources and aging processes (Fig. 7a). Cases 22APR93 and 5DEC93 refer to tropical, bimodal distribution, 7APR93 refers to midlatitude, open distribution and 11APR93 refers to tropical semi open distribution. For details of the impact of air masses on aerosol size distributions, see Covert et al. (1996). Calculated $L_{m}$ is shown for cases 7APR 93 and 11APR93 (the other two cases are close to 7APR93) (Fig. 7b).

An example of submicron aerosol measured at a continental site is shown here based on measurements of aerosol size distribution at an alpine site (Jungfraujoch; $3580 \mathrm{~m}$ asl, Switzerland) from March 1997 to May 1998 (Weingartner et al., 1999). Measurements were taken using a scanning mobility particle sizer (SMPS, TSI 3934), comprising a DMA (TSI 3071) and CNC (TSI 3022), monitoring the size distribution of particles mobility diameters $d_{p}=18-750 \mathrm{~nm}$. The cases are grouped based on the liquid water content (LWC) values, as a measure of the cloudiness conditions. Figure 8a shows the measured size distributions. Calculated $L_{m}$ are shown in Fig. $8 b$ for cases of clear sky and very dense cloudiness.

Similar results are obtained using submicron data from other field experiments (Van Dingenen et al., 1995; Jensen et al., 1996; Brechtel et al., 1998). Calculated $L_{m}$ for submicron data, particularly for accumulation mode, shows that BCS is not effective, except for very intense rainfall intensities. In contrast, the presence of coarse mode shows that $L_{m}$ has high values and therefore large particles can be removed fast even for moderate precipitation rates $\left(R \sim 1 \mathrm{~mm} \mathrm{hr}^{-1}\right)$. 


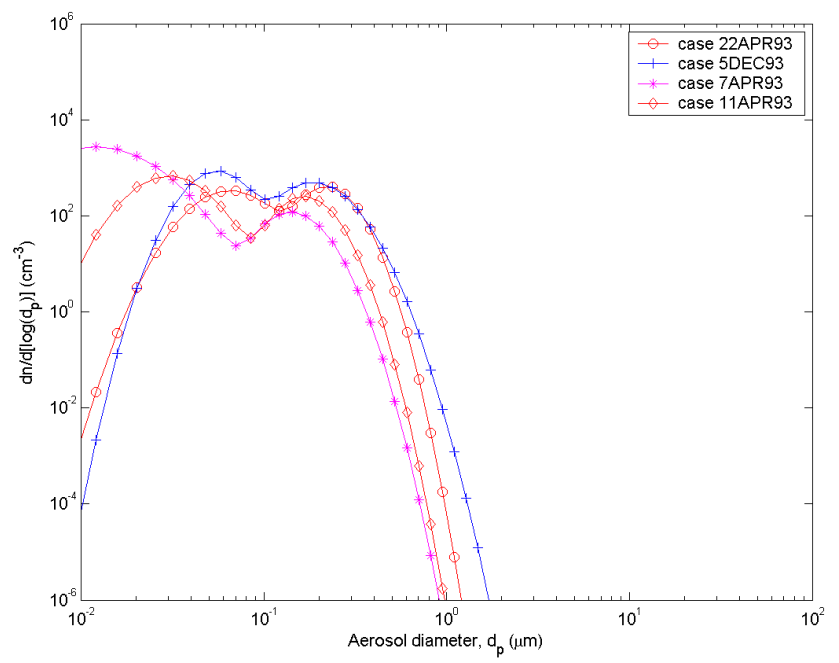

Fig. 7a. Several cases of marine boundary layer aerosol size distribution observed in mid-Pacific during 1992 and 1993 (Covert et al., 1996)

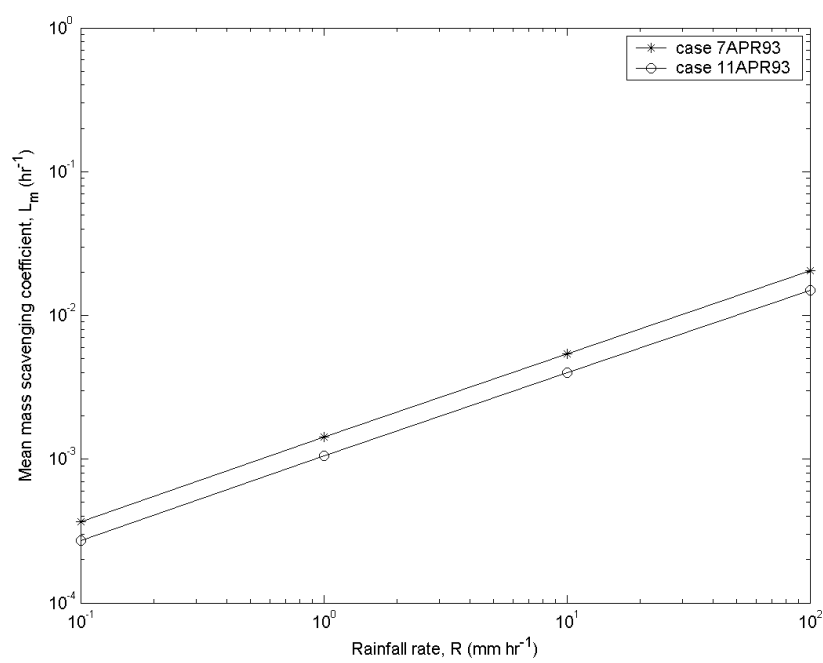

Fig. 7b. Corresponding mean mass scavenging coefficient, $L_{m}$ for two typical cases.

For a persistent precipitation regime, large particles can be removed shortly after the rain starts and BL remains populated with accumulation particles that are less removed by BCS. However, nucleation scavenging followed by ICS can be more effective in removal of the particles from this part of the size spectrum. This study shows the importance of BCS for large particles in several cases: windy conditions over MBL when coarse particles dominate the aerosol mass, dust layer events with potential large particles, and possible pollution events with large and fine particles. These cases tend to be more variable and transitory than the accumulation mode.

For a given aerosol distribution case, the BCS coefficient can be expressed as $L_{m}=a R^{b}$ where $L_{m}$ is in units of $\mathrm{hr}^{-1}$,

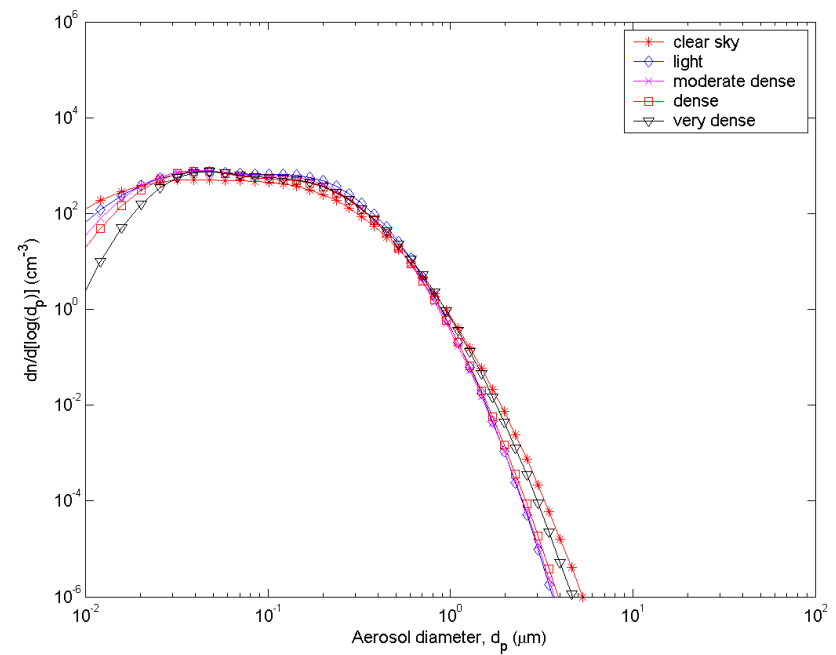

Fig. 8a. Alpine aerosol measurements during 1997-1998 at Jungfraujoch (3500 m asl) Switzerland for different cloudiness conditions (Weingartner et al., 1999).

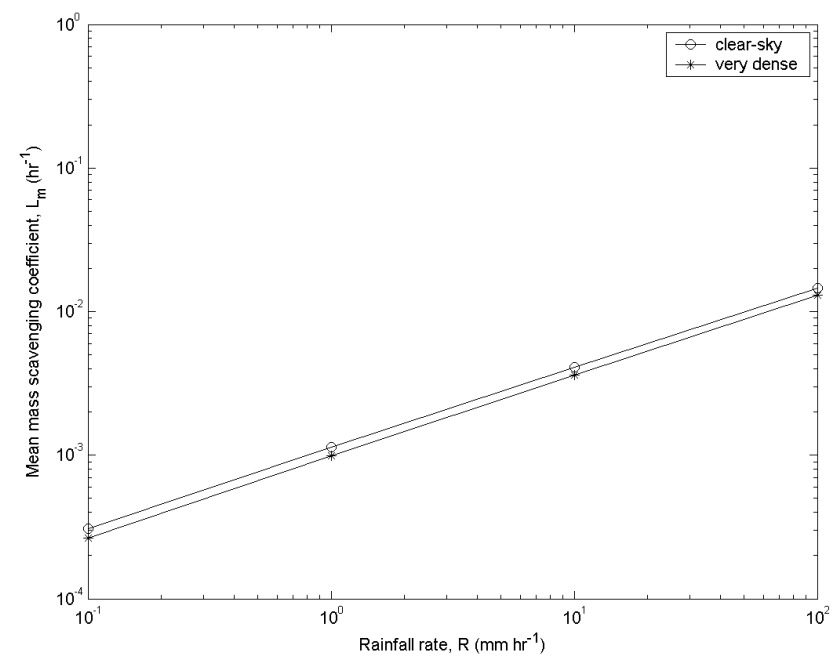

Fig. 8b. Corresponding mean mass scavenging coefficient, $L_{m}$ for two typical cases.

$R$ is the rainfall rate (in units of $\mathrm{mm} \mathrm{hr}^{-1}$ ) and $a$ and $b$ are coefficients that depend on aerosol characteristics. Table 3 summarizes the results of this work and several reports in recent literature. We note that for cases with coarse particles, $a$ is in the interval [0.24-0.88] and $b=0.7$, while for the ICS, $a=1.26$ and $b=0.78$. For the cases dominated by submicron particles, $a$ is in the interval $[0.1-1.13] \times 10^{-3}$, except for the case of Jylha (1999) who assumed a constant value of $E=0.02$ for particles with diameters in the range [0.3-0.9] $\mu \mathrm{m}$. The values of $b$ are in the interval [0.59-0.94]. We note that generally, the results of this work are comparable with previous calculations for scavenging of large particles and in good agreement with the experimental values re- 
Table 3. Summary of below-cloud scavenging coefficient (in units of $\mathrm{hr}^{-1}$ ) expressed as $a R^{b}$ (where the rainfall rate $R$ is in units of mm $\mathrm{hr}^{-1}$ )

\begin{tabular}{|c|c|c|c|}
\hline $\mathrm{a}$ & $\mathrm{b}$ & Reference & Note \\
\hline \multicolumn{4}{|c|}{ Cases with coarse aerosol mode } \\
\hline 0.24 & 0.70 & This work & (a) Urban \\
\hline 0.46 & 0.70 & $"$ & (a) Remote cont. \\
\hline 0.50 & 0.70 & $”$ & (a) Marine \\
\hline 0.45 & 0.70 & $"$ & (a) Rural \\
\hline 0.68 & 0.70 & $"$ & (a) Free trop. \\
\hline 0.34 & 0.70 & $"$ & (a) Polar \\
\hline 0.88 & 0.70 & $"$ & (a) Desert \\
\hline 0.80 & 0.70 & $"$ & (b) Marine \\
\hline 0.30 & 0.70 & $"$ & (c) Marine \\
\hline 0.70 & 0.70 & $"$ & (d) Dust layer \\
\hline 0.36 & $0.67-0.76$ & Okita et al. (1996) & (e) \\
\hline 1.26 & 0.78 & Scott (1982) & (f) \\
\hline \multicolumn{4}{|c|}{ Cases with predominant submicron particles } \\
\hline $0.84 \times 10^{-3}$ & 0.59 & Sparmacher et al. (1993) & (g) $\left(d_{p}=0.23 \mu \mathrm{m}\right)$ \\
\hline $1.13 \times 10^{-3}$ & 0.60 & Sparmacher et al. (1993) & (g) $\left(d_{p}=0.46 \mu \mathrm{m}\right)$ \\
\hline $0.92 \times 10^{-3}$ & 0.94 & Sparmacher et al. (1993) & $(\mathrm{g})\left(d_{p}=0.98 \mu \mathrm{m}\right)$ \\
\hline $0.62 \times 10^{-3}$ & 0.61 & Sparmacher et al. (1993) & $(\mathrm{g})\left(d_{p}=2.16 \mu \mathrm{m}\right)$ \\
\hline $2.50 \times 10^{-2}$ & 0.92 & Jylha (1999) & (h) Radionuclides \\
\hline $0.85-5.00 \times 10^{-3}$ & $0.59-0.61$ & This work & (i) Marine \\
\hline $0.10-0.14 \times 10^{-3}$ & 0.59 & 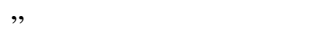 & (j) Marine \\
\hline $0.86 \times 10^{-3}$ & 0.59 & $"$ & (k) Alpine \\
\hline
\end{tabular}

(a) Calculations are based on the aerosol types by Jaenicke (1993); (b) Calculations are for marine aerosol data based on O'Dowd et al. (1997); (c) Calculations are for marine aerosol data from Bates et al. (1998); (d) Calculations are for the dust layer aerosol data from de Reus et al. (2000); (e) Experimental estimation for total wet scavenging by Okita et al. (1996); (f) Model calculated in-cloud scavenging coefficient for aerosol particles grown at the size of cloud droplet with $d_{p}=10 \mu \mathrm{m}$ particle (see text for details); (g) Experimental values by Sparmacher et al. (1993) for four diameters of aerosol particle collected by rain; (h) Model calculated values for particles with diameters in the range [0.3-0.9] $\mu \mathrm{m}$ and assumed $E=0.02$ (Jylha, 1999); (i) Calculations based on submicron marine aerosol from Raes et al. (1993); Calculations based on submicron marine aerosol from Covert et al. (1996); Calculations based on alpine submicron aerosol from Weingartner et al. (1999).

ported by Sparmacher et al. (1993) for submicron particles. The results of Sparmacher et al. (1993) used in these comparisons are based on the experimental determination of BCS coefficient during rain events for four selected aerosol diameters given in Table 3. The impact of selective scavenging of various parts of the aerosol spectrum results in a strong dependence of the 0.5 -folding time due to BCS, defined as $\tau=\ln (2) / L\left(d_{p}\right)$, on aerosol diameter (Fig. 9). Thus, for $R \sim 1 \mathrm{~mm} \mathrm{hr}^{-1}, \tau$ is of the order of 1 hour for very small and coarse particles and it becomes of the order of days or larger for particles in the accumulation mode. Results suggests that values of $L_{m}$ calculated using three aerosol modes are appropriate only for short time after beginning of precipitation, and then gradually as the large particles are depleted, $L_{m}$ tends to values characteristic to accumulation mode. Finally, we illustrate changes in the aerosol size distribution due to the BCS process. We chose to show changes in the aerosol volume distribution $d V / d \log \left(d_{p}\right)$ because this is directly related to changes in aerosol mass distribution. The initial aerosol volume distribution corresponds to a remote continental type. Figure 10a shows the change of aerosol volume distribution after one hour of rain with a rainfall rate $R=1 \mathrm{~mm} \mathrm{hr}^{-1}$, $10 \mathrm{~mm} \mathrm{hr}^{-1}$ and $100 \mathrm{~mm} \mathrm{hr}^{-1}$. The initial aerosol volume distribution is marked by a solid line and we note that after one hour, for moderate rain of intensity, $R=10 \mathrm{~mm} \mathrm{hr}^{-1}$, the changes are dramatic (most of the coarse particle volume is removed). Figure $10 \mathrm{~b}$ illustrates the changes in the aerosol volume distribution for $R=10 \mathrm{~mm} \mathrm{hr}^{-1}$ after a duration of rain $t=0.5 \mathrm{hr}, 1 \mathrm{hr}$ and $10 \mathrm{hr}$. We note that after 0.5 and 1 hour of rain, the coarse aerosol volume is depleted. In these plots only the BCS was considered, while in more realistic situations encountered during filed measurements, the aerosol size distribution could change due to other interactions not included here. 


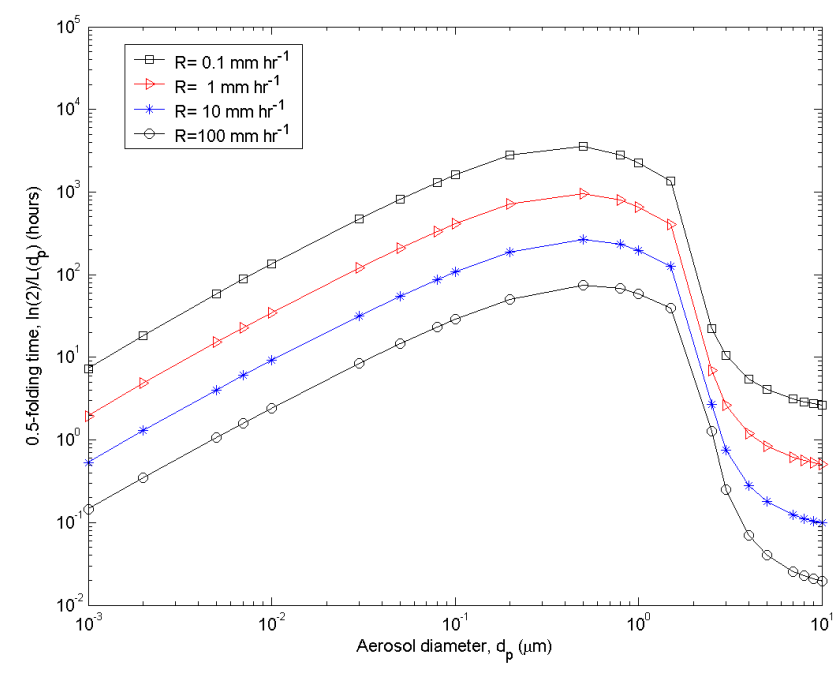

Fig. 9. Aerosol 0.5-folding time due to below-cloud scavenging process only, versus aerosol particle diameter.

\section{Conclusions}

We estimated the below-cloud scavenging (BCS) coefficients of aerosols by rainfall for several observed aerosol size distributions reported from field experiments. The method employed is based on explicit calculations of the efficiency of collision between a raindrop and aerosol particles. Results show that BCS coefficient depends mainly on the aerosol size distribution parameters and on rainfall intensity. We found that:

(a) For a given aerosol size, the BCS coefficient varies about two orders of magnitude for a variation of rainfall rate between 0.01 and $100 \mathrm{~mm} \mathrm{hr}^{-1}$. For a given rainfall rate, BCS coefficient varies significantly with aerosol diameter.

(b) The BCS is effective for very small particles (with diameters less than $0.01 \mu \mathrm{m}$ ) and for coarse particles (with diameters larger than $2 \mu \mathrm{m}$ ). For these cases, the BCS coefficients have values comparable with in-cloud scavenging coefficients. For rainfall rate $R \sim 1 \mathrm{~mm} \mathrm{hr}^{-1}$, the 0.5 -folding time of these particles due to BCS is of the order of one hour. This suggests that for a model description of detailed rapid changes in aerosol size distribution in the BL, it is necessary to use bin defined BCS coefficients, $L\left(d_{p}\right)$, and high frequency values of rainfall rate. The presented results show that the BL aerosol size distribution with coarse mode is affected by BCS very shortly after rain starts (in a fraction of one hour). After the removal of very small and coarse particles, the below-cloud aerosol size distribution is dominated by particles in the accumulation mode.

(c) For low and moderate rainfall rates $(R \sim 0.1-10 \mathrm{~mm}$ $\mathrm{hr}^{-1}$ ), the BCS is negligible for particles in the range

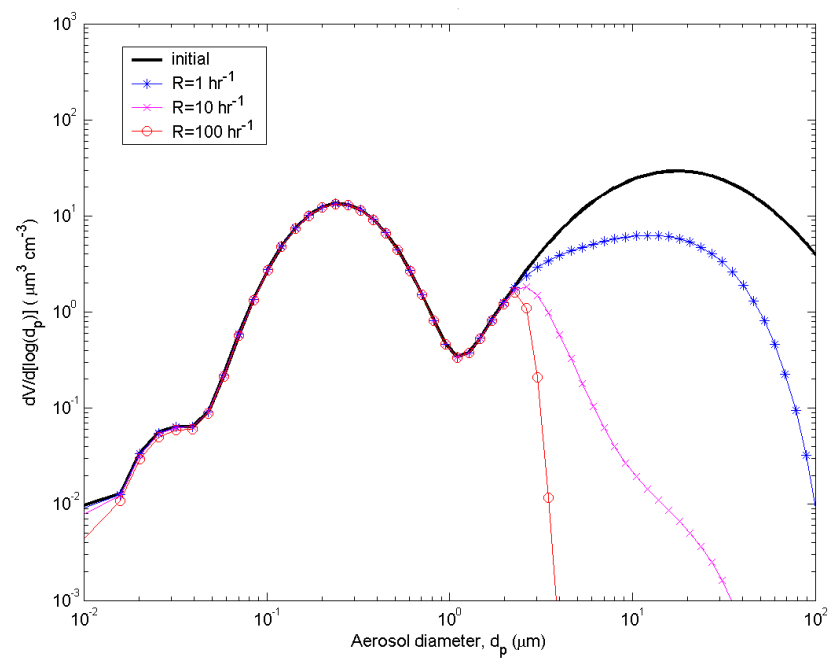

Fig. 10a. Calculated changes in the aerosol volume distribution after one hour of rain with a rainfall rate $R=1 \mathrm{~mm} \mathrm{hr}^{-1}, 10 \mathrm{~mm}$ $\mathrm{hr}^{-1}$ and $100 \mathrm{~mm} \mathrm{hr}^{-1}$.

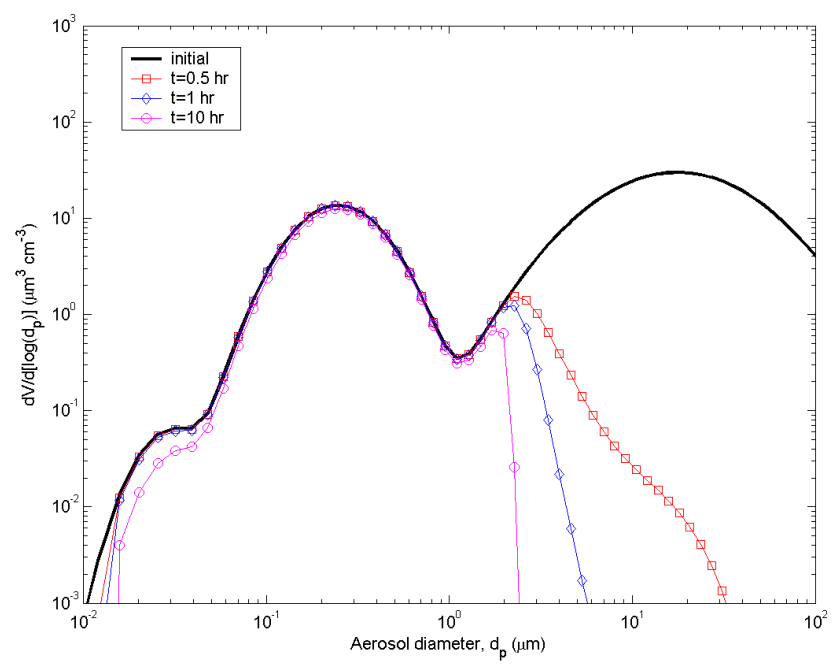

Fig. 10b. Calculated changes in the aerosol volume distribution for $R=10 \mathrm{~mm} \mathrm{hr}^{-1}$ after a duration of rain $t=0.5 \mathrm{hr}, 1 \mathrm{hr}$ and 10 $\mathrm{hr}$. The initial aerosol volume distribution is marked by a solid line. Shown changes are due to below-cloud scavenging process only.

[0.1-1] $\mu \mathrm{m}$ in comparison with in-cloud scavenging . For very intense precipitation $\left(R \sim 100 \mathrm{~mm} \mathrm{hr}^{-1}\right)$, BCS of these particles becomes significant. The results of this work have practical significance for modeling rapid changes of aerosol size distribution in the BL as in the cases of field experiments with continuous high frequency measurements of aerosol size spectrum. Thus, in case of precipitation in the measurement domain, the BCS can contribute substantially to the removal of fine particles (produced by nucleation events, for example) and coarse particles (such as dust and sea-salt aerosols). 
Another possible application of this work is in the evaluation and assessment of the efficiency of artificial removal of particles produced during accidental pollution events near the ground. In absence of precipitation, the artificial spraying water drops over the contaminated area can substantially remove particles from the atmosphere and can minimize the amount of material that will be long-range transported by advection.

Acknowledgements. The author thanks Kevin Noone and an anonymous reviewer for their comments and suggestions that improved the manuscript.

\section{References}

Bates, T. S., Kapustin, V., Quinn, P. K., Covert, D. S., Coffman, D. J., Mari, C., Durkee, P. A., De Bruyn, W. J., and Saltzman, E. S.: Processes controlling the distribution of aerosol particles in the lower marine boundary layer during the First Aerosol Characterization Experiment (ACE1), J. Geophys. Res., 103, D13, 16369-16383, 1998.

Brechtel, F. J., Kreidenweis, S. M., and Swan, H. B.: Air mass characteristics, aerosol particle number concentrations, and number size distributions at Maquarie Island during the First Aerosol Characterization Experiment (ACE1), J. Geophys. Res., 103, D13, 16351-16367, 1998.

Byrne, M. A. and Jennings, S. G.: Scavenging of sub-micrometer aerosol particles by water drops, Atmos. Environ., 27A, 14, 2099-2105, 1993.

Chang, T. Y.: Estimate of nitrate formation in rain and snow systems, J. Geophys. Res., 91, D2, 2805-2818, 1986.

Charlson, R. J., Schwartz, S. E., Hales, J. M., Cess, R. D., Coakley, J. A., Hansen, J. E., and Hofmann, D. J.: Climate forcing by anthropogenic aerosols, Science 255, 423-430, 1992.

Covert, D. S., Kapustin, V. N., Bates, T. S., and Quinn, P. K.: Physical properties of marine boundary layer aerosol particles of the mid-Pacific in relation to sources and meteorological transport, J. Geophys. Res., 101, D3, 6919-6930, 1996.

Dana, M. T. and Hales, J. M.: Statistical aspects of the washout of polydisperse aerosols, Atmos. Environ., 10, 45-50, 1976.

De Reus, M., Dentener, F., Thomas, A., Borrmann, S., Strom, J., and Lelieveld, J.: Airborne observations of dust aerosol over the North Atlantic during ACE2: Indications for heterogeneous ozone destruction, J. Geophys. Res., 105, D12, 15 263-15 275, 2000.

Flossmann, A. I., Hall, W. D., and Pruppacher, H. R.: A theoretical study of the wet removal of atmospheric pollutants. Part I: The redistribution of aerosol particles captured through nucleation and impaction scavenging by growing cloud drops, J. Atmos. Sci., 42, 4, 583-606, 1985.

Flossmann, A. I., Pruppacher, H. R., and Topalian, J. H.: A theoretical study of the wet removal of atmospheric pollutants. Part II: The uptake and redistribution of $\left(\mathrm{NH}_{4}\right)_{2} \mathrm{SO}_{4}$ particles and $\mathrm{SO}_{2}$ gas simultaneously scavenged by growing cloud drops, J. Atmos. Sci., 44, 20, 2912-2923, 1987.

Greenfield, S.: Rain scavenging of radioactive particulate matter from the atmosphere, J. Meteor., 14, 115-125, 1957.

Grover, S. N., Pruppacher, H. R., and Hamielec, A. E.: A numerical determination of the efficiency with which spherical aerosol par- ticles collide with spherical water drops due to inertial impaction and phoretic and electric forces, J. Atmos. Sci., 34, 1655-1663, 1977.

IPCC: Climate Change 1995: The Science of Climate Change, Cambridge University Press, pp. 572, 1996.

Jaenicke, R.: Tropospheric aerosols, in: Aerosol-cloud-climate interactions, (Ed) Hobbs, P., Academic Press, San Diego, CA, pp. 1-31, 1993.

Jensen, T. L., Kreidenweis, S. M., Kim, Y., Sievering, H., and Pszenny, A.: Aerosol distributions in the North Atlantic marine boundary layer during Atlantic Stratocumulus Transition Experiment/Marine Aerosol and Gas Exchange, J. Geophys. Res., 101, D2, 4455-4467, 1996.

Junge, C. E.: Air chemistry and radioactivity, Academic Press, New York and London, pp. 382, 1963.

Jylha, K.: Empirical scavenging coefficients of radioactive substances released from Cernobyl, Atmos. Environ., 25A, 263-270, 1991.

Jylha, K.: Relationship between the scavenging coefficient for pollutants in precipitation and the radar reflectivity factor. Part I: Derivation, J. of Applied Met., 38, 1421-1434, 1999.

Joss, J., J. C. Thamas, and A. Waldwogel: The variation of raindropsize distributions at Lacarno. Proc. Int. Conf. Cloud Physics, Toronto, Amer. Meteor. Soc., 369-373, 1968.

Kessler, E.: On the distribution and continuity of water substance in atmospheric circulations, Meteorol. Monographs No. 32, 84 pp., Am. Meteorol. Soc., Boston, Mass., 1969.

Marshall, J. S. and Palmer, W. M.: The distribution of raindrop with size, J. Meteor., 5, 165-166, 1948.

Mircea, M., Stefan, S., and Fuzzi, S.: Precipitation scavenging coefficient: influence of measured aerosol and raindrop size distributions, Atmos. Environ., 34, 5169-5174, 2000.

O'Dowd, M., Smith, H. , Consterdine, I. E., and Lowe, J. A.: Marine aerosol, sea-salt, and the marine suphur cycle: a short review, Atmos. Environ., 31, 1, 73-80, 1997.

Okita, T., Hara, H., and Fukuzaki, N.: Measurements of atmospheric $\mathrm{SO}_{2}$ and $\mathrm{SO}_{4}$, and determination of the wet scavenging of sulfate aerosol for the winter monsoon season over the sea of Japan, Atmos. Environ., 30, 22, 3733-3739, 1996.

Pruppacher H. R. and Klett J. D.: Microphysics of clouds and precipitation, Kluwer Academic Publishers, Dordrecht, Boston, London, pp. 954, 1997.

Radke, L. F., Hobbs, P. V., and Eltgroth, M. W.: Scavenging of aerosol particles by precipitation, J. Atmos. Sci., 19, 715-722, 1980.

Raes, F., Van Dingenen, R., Cuevas, E., Van Velthoven, P. F. J., and Prospero, J. M.: Observations of aerosols in the free troposphere and marine boundary layer of the subtropical Northeast Atlantic: Discussion of processes determining their size distribution, J. Geophys. Res., 102, D17, 21 315-21 328, 1997.

Rasch, P. J., Feichter, J., Law, K., et al.: A comparison of scavenging and deposition processes in global models: results from the WCRP Cambridge Workshop of 1995, Tellus, 52B, 1025-1056, 2000.

Schumann, T.: Aerosol and hydrometeor concentrations and their chemical composition during winter precipitation along a mountain slope-III. Size-differentiated in-cloud scavenging efficiencies, Atmos. Environ., 25A, 3/4, 809-824, 1991. 
Scott, B. C.: Theoretical estimates of the scavenging coefficient for soluble aerosol particles as a function of precipitation type, rate and altitude, Atmos. Environ., 16, 7, 1753-1762, 1982.

Seinfeld, J. H. and Pandis, S. N.: Atmospheric Chemistry and Physics, Wiley, New York, pp. 1326, 1998.

Sekhon, R. S., and R. C. Srivastva: Doppler radar observations of drop-size distributions in a thunderstorm, J. Atmos. Sci., Vol. 28, 983-994, 1971.

Slinn, W. G. N.: Precipitation scavenging, in Atmospheric Sciences and Power Production 1979, Chap 11. Division of Biomedical Environmental Research, U.S. Department of Energy, Washington, D.C., 1983.

Slinn, W. G. N. and Hales, J. M.: A reevaluation of the role of thermophoresis as a mechanism of in- and below-cloud scavenging, J. Atmos. Sci., 28, 1465-1471, 1971.

Sparmacher, H., Fulber, K., and Bonka, H.: Below-cloud scavenging of aerosol particles: Particle-bound radionuclide - Experimental, Atmos. Environ., 27A, 4, 605-618, 1993.

Ten Brink, H. M., Schwartz, S. E., and Daum, P. H.: Efficient scavenging of aerosol sulfate by liquid-water clouds, Atmos. Environ., 21, 9, 2035-2052, 1987.

Tinsley, B. A., Rohrbaugh, R. P., Hei, M., and Beard, K. V.: Effects of image charges on scavenging of aerosol particles by cloud droplets and on droplet charging and possible ice nucleation processes, J. Atmos. Sci., 57, 2118-2134, 1999.

Twomey, S.: Aerosols, clouds, and radiation, Atmos. Environ., 25A, 2435-2442, 1991.

Ulbrich, C. W.: Natural variations in the analytical form of the raindrop size distribution, J. Climate and Applied Meteor., Vol. 22, 1764-1775, 1983.

Van Dingenen, R., Raes, F., and Jensen, N. R.: Evidence for anthropogenic impact on number concentration and sulfate content of cloud-processed aerosol particles over the North Atlantic, J. Geophys. Res., 100, D10, 21 057-21 067, 1995.

Wang, P. K. and Pruppacher, H. R.: An experimental determination of the efficiency with which aerosol particles are collected by water drops in subsaturated air, J. Atmos. Sci., 34, 1664-1669, 1977.

Wang, P. K., Grover, S. N., and Pruppacher, H. R.: On the effect of electric charges on the scavenging of aerosol particles by clouds and small raindrops, J. Atmos. Sci., 35, 1735-1743, 1978.

Weingartner, E., Nyeki, S., and Baltensperger, U.: Seasonal and diurnal variation of aerosol size distributions $\left(10<d_{p}<750 \mathrm{~nm}\right)$ at a high-alpine site (Jungfraujoch $3580 \mathrm{~m}$ asl), J. Geophys. Res., 104, D21, 26 809-26 820, 1999. 